\title{
Viscoelastic Response of Graphite Platelet and CTBN Reinforced Vinyl Ester Nanocomposites
}

\author{
Brahmananda Pramanik, P. Raju Mantena* \\ Department of Mechanical Engineering, University of Mississippi, Oxford, USA. \\ Email: ${ }^{*}$ meprm@olemiss.edu
}

Received August 20 ${ }^{\text {th }}, 2011$; revised October $3^{\text {rd }}, 2011$; accepted October $17^{\text {th }}, 2011$.

\begin{abstract}
Developing stronger, safer and more cost-effective structural materials for the new generation naval ships is the focus of ongoing research at University of Mississippi. The light-weight nanoparticle reinforced glass/carbon polymeric based composites and structural foams for blast, shock and impact mitigation are emphasized in this research. Derakane 510A-40 brominated vinyl ester nanocomposite resin systems are considered to be used in the composite face sheets of sandwich structures with fire-resistant foam core to reduce flammability along with optimal flexural rigidity, vibrational damping and enhanced energy absorption. In this work, the viscoelastic performance of 1.25 and 2.5 weight percent exfoliated graphite nanoplatelet $(x G n P)$ added with 10 weight percent Carboxy Terminated Butadiene Nitrile $(C T B N)$ reinforced brominated vinyl ester nanocomposites are studied. A Dynamic Mechanical Analyzer (DMA)-TA Instruments Model Q800 was used to obtain the viscoelastic properties, modulus (stiffness), creep/stress relaxation, and damping (energy dissipation), of the exfoliated graphite platelet and CTBN reinforced brominated vinyl ester. Effects of frequency (time) on the viscoelastic behavior were investigated by sweeping the frequency over three decades: 0.01, 0.1, 1.0 and $10 \mathrm{~Hz}$, temperature range from $30^{\circ} \mathrm{C}$ to $15^{\circ} \mathrm{C}$ at $4^{\circ} \mathrm{C}$ per minute step rate. Master curves were generated by time-temperature superpositioning (TTS) of the experimental data at $50^{\circ} \mathrm{C}$ reference temperature. Addition of CTBN in $x G n P$ reinforced brominated vinyl ester composites resulted in greater intrinsic material damping, indicating the possibility of higher energy absorption with the new configuration.
\end{abstract}

Keywords: Nanocomposite, CTBN, Viscoelastic, TTS, Material Damping, Energy Absorption

\section{Introduction}

The objective of ongoing research at University of Mississippi is developing stronger, safer and more cost-effective structural materials for the new generation naval ships. The emphasis is on the light-weight nanoparticle reinforced glass/carbon polymeric based composites and structural foams for blast, shock and impact mitigation. The optimal flexural rigidity, vibrational damping and enhanced energy absorption characteristics of composite structures are extensively investigated in this research.

Thermoset resins, such as vinyl ester, are typically brittle. To improve their fracture resistance or toughness, they are usually blended or reacted with different additives and modifiers, which generally forms a second dispersed phase. The most frequently used modifiers are liquid rubbers. The morphology of the final modified thermoset can significantly affect the toughening mechanism and consequently its fracture toughness [1-3].

Auad et al. [1] investigated the mechanical behavior of vinyl ester resin cured with styrene and modified with liquid rubber CTBN. A sharp drop in density causing detrimental fracture toughness was observed in higher CTBN concentrations (>10 wt\%). Balakrishnan et al. [2] examined the fracture behavior of rubber dispersed epoxy and inferred cavitations, yielding, plastic deformation of matrix, crack diversion and energy dissipation caused by rubber particles which contribute to the improvement of the ductility of the epoxy nanocomposite system. Frohlich et al. [3] suggested the compatibility matching as the key to novel phase-separated nanocomposites with significantly improved toughness.

The study of time dependent deformation process is highly relevant when long-term applications are in consideration. Polymeric composites are viscoelastic in nature and show the time-temperature dependant behavior. The time-dependent deformation of materials subjected to a constant stress is defined as creep [4]. In multiple literatures, the creep behavior of polymer/clay nanocom- 
posites have been modeled [4-9], and proposed that nanoparticles improve the creep resistance of polymer matrices depending on success in level of exfoliation.

The fatigue strength, cyclic deformation and strain incompatibility of clay-reinforced nylon have been demonstrated by Yang et al. [4] Fatigue strength slightly increased by addition of clay reinforcement to nylon 6 . The cyclic deformation has been examined applying stressstrain hysteresis loops. The strain incompatibility near the phase boundary caused both relaxation of three dimensional stress field and extraction of clay platelets in the nano-composites under study.

Tensile compliance of the nano-clay reinforced Polyethylene composites was investigated by Pegoretti et al. [5]. The viscoelastic component is low corresponding only to a few percent of the compliance even at relatively high stresses. The compliance of the composites is only slightly lower than that of the neat rPET, the Cloisite ${ }^{\circledR}$ $25 \mathrm{~A}$ reinforcement being somewhat stronger. Both clays were illustrated beneficial effect on the dimensional stability of the composites as compared to the neat rPE, the creep rate did not rise at long time periods.

Galgali et al. [6] presented an experimental investigation on the creep behavior of molten polypropylene organically modified clay nanocomposites and concluded that the solid-like rheological response of this nanocomposite develops from large frictional interactions of the clay crystallites. Compatibilizer showed a significant influence in modifying the rheological behavior.

Non-linear time dependent creep of polyethylene (PE) montmorillonite layered silicate (MLS) nanocomposites was investigated by Ranade et al. [7]. Non-linearity in the creep response was modeled using the Burger model and the tensile-creep response was attributed to dispersion effects with marginal effects of crystallinity.

Perez et al. [8] studied the clay content and temeperature dependent creep behavior of biodegradable composites based on starch/polycaprolactone commercial blends reinforced with organo-modified nanoclay, processed by melt-intercalation. The experimental response was correlated with Findlay's power law and Burger's model. This investigation showed that the addition of clay to the neat matrix leads to a significant improvement of creep resistance.

The effects of incorporating various montmorillonite nanoclays into several starch samples were by rheologically examined by Chiou et al. [9]. Frequency sweep and creep results for starch-nanoclay samples at room temperature indicated that the Cloisite $\mathrm{Na}+$ samples formed more gel-like materials than the other nanoclay samples. The Cloisite $\mathrm{Na}+$ samples exhibited a large increase in modulus at higher temperature. In contrast, the more hydrophobic nanoclay samples had comparable modulus values to the pure starch sample. These results suggested that during gelatinization, the leached amylose interacted with the Cloisite $\mathrm{Na}+$ interlayer, producing better reinforcement and higher modulus values.

These multiple studies showed the significance of characterizing visoelastic behavior of nanocomposites in their respective application fields. Hence, investigating time-temperature depended response of rubber-toughened nanocomposites is an important consideration. The aim of this paper is to describe the viscoelastic behavior of vinyl ester nanoreinforced composites added with an almost unreactive liquid carboxy terminated butadiene nitrile (CTBN) rubber, a toughening agent for thermoset resins. The viscoelastic response of Carboxy Terminated Butadiene Nitrile (CTBN) on the viscoelastic behavior of Derakane 510A-40 brominated vinyl ester reinforced with 1.25 and $2.5 \mathrm{wt} \%$ exfoliated graphite nano platelets was studied using dynamic mechanical analyzer (DMA). Single frequency and frequency sweep across 3 decades: $0.01,0.1,1.0$ and $10 \mathrm{~Hz}$ were applied over $30^{\circ} \mathrm{C}$ to $150^{\circ} \mathrm{C}$ temperature range at a $4^{\circ} \mathrm{C} / \mathrm{min}$ step rate. The time- temperature superposition (TTS) principle was applied to develop master curves of the dynamic storage modulus at a reference temperature of $50^{\circ} \mathrm{C}$.

\section{Experimental Techniques}

\subsection{Dynamic Mechanical Analyzer (DMA)}

DMA tests were performed in accordance with ASTM D4065-01 standard [10]. TA Instruments Model Q 800 DMA (Figure 1) is a stress-controlled Combined Motor and Transducer (CMT) machine where the motor applies a force and displacement sensors measure strain, force and amplitude in the form of raw signals recorded by the machine [11]. Experiments were performed using the single-cantilever clamp. Hence the most of the strain oc-

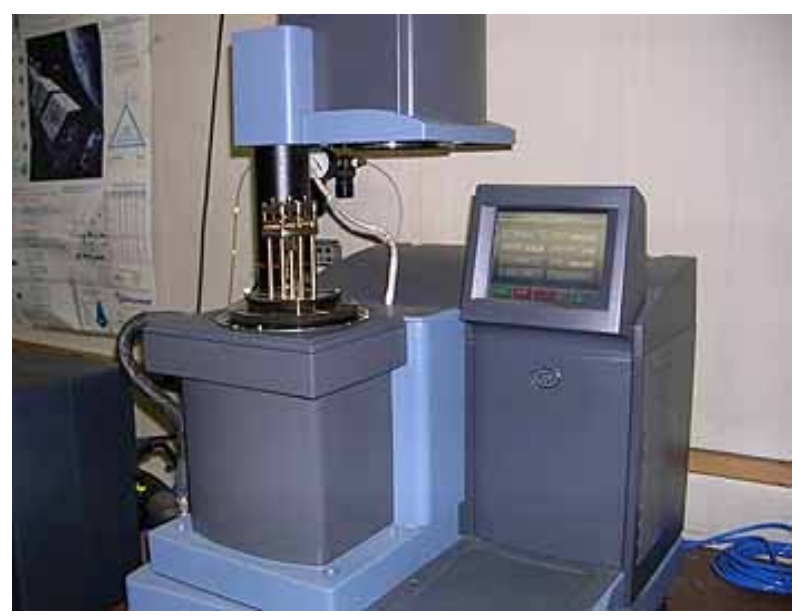

Figure 1. TA Instruments Model Q800 DMA for dynamic tests [11]. 
curred at the sample surface, while the center experienced no strain. The stress and strain equations, applied in these experiments, are based on theory of linear visoelasticity of the materials (Equations (1) to (4)).

$$
\begin{aligned}
& E=\frac{K_{S}}{F_{C}} \cdot \frac{L^{3}}{12 I}\left[1+\frac{12}{5}(1+v)\left(\frac{t}{L}\right)^{2}\right] \\
& F_{c}=0.7616-0.02713 \sqrt{\frac{L}{t}}+0.1038 \ln \left(\frac{L}{t}\right) \\
& \sigma_{x}=\frac{6 P L}{w t^{2}} \\
& \varepsilon_{x}=\frac{3 \delta t F_{c}}{L^{2}\left[1+\frac{12}{5}(1+v)\left(\frac{t}{L}\right)^{2}\right]}
\end{aligned}
$$

where, $E=$ elastic modulus, $K_{s}=$ measured stiffnes, $F_{c}=$ clamping correction factor, $L=$ clamp span length, $I=$ sample moment of inertia, $v=$ Poisson's ratio, $t=$ sample thickness, $\sigma_{x}=$ stress, $P=$ applied load, $w=$ width of the specimen, $\varepsilon_{X}=$ strain, $\delta=$ amplitude of deformation.

The viscoelastic properties, such as, modulus (stiffness) and damping (energy dissipation), of the exfoliated graphite platelet added with CTBN reinforced brominated vinyl ester were studied over a range of temperature and frequency. Creep and stress relaxation experiments were also conducted using DMA.

\subsection{Single Frequency Dynamic Test}

Dynamic mechanical analysis was carried out using the TA Instrument model DMA Q800 V7.5 on rectangular cross-sectioned specimens under single-cantilever clamping mode, with a span length of $17.5 \mathrm{~mm}$. The 1.25 and 2.5 weight percent nanoclay, graphite platelet and graphite platelet added with 10 weight percent Carboxy Terminated Butadiene Nitrile (CTBN) reinforced brominated vinyl ester nanocomposites were characterized and compared with the base pure brominated vinyl ester thermoset composite under single frequency-temperature ramp method. Samples of $35 \mathrm{~mm} \times 10 \mathrm{~mm} \times 1.6 \mathrm{~mm}$ thick were clamped with 30 gm clamp mass and subjected to 1 $\mathrm{Hz}$ single frequency with $25 \mu \mathrm{m}$ displacement amplitude assuming linear visco-elastic characterization. Test temperature was equilibrated at $30^{\circ} \mathrm{C}$ and maintained isothermal for 5 minutes, and then elevated with $3{ }^{\circ} \mathrm{C} / \mathrm{min}$ steps up to $150^{\circ} \mathrm{C}$ in test duration. Three specimens were tested from each configuration of the nanocomposites. The output data were processed by Rheology data analysis software to produce characteristic graphs [11].

\subsection{Multi-Frequency Dynamic Test}

DMA measurements included frequency sweep with time temperature steps, to which time-temperature super-position (TTS) was applied to predict the long-term time dependent properties of the material. The dynamic storage modulus $\left(E^{\prime}\right)$ and damping of nano-reinforced brominated 510A-40 vinyl ester specimens were characterized as a function of temperature and frequencies. Dynamic mechanical testing was used to perform multifrequency measurements with accelerated temperature and theoretical time-temperature superposition post-processing of the data. Effects of CTBN inclusion in exfoliated graphite platelet reinforcement were investigated.

Vinyl ester nanocomposites were characterized by performing a multi-frequency isothermal mode test, in which the sample is equilibrated at different temperatures and subjected to a series of frequencies. Specimens with dimensions of $35 \mathrm{~mm} \times 10 \mathrm{~mm} \times 1.6 \mathrm{~mm}$ were subjected to frequencies of $0.01,0.1,1.0$ and $10 \mathrm{~Hz}$ with a temperature step rate of $4^{\circ} \mathrm{C}$ per minute starting from $30^{\circ} \mathrm{C}$ (RT) to $150^{\circ} \mathrm{C}$. Only $25 \mu \mathrm{m}$ displacement amplitude was applied for the test since the analysis assumes linear domain for viscoelastic characterization, and two specimens were tested from each configuration. The raw data was then processed using the Rheology data analysis software to generate the master curves.

\subsection{Creep and Stress Relaxation}

The creep and stress-relaxation response of brominated vinyl ester and its nanocomposites was investigated using the DMA. Nano-reinforced brominated 510A-40 vinyl ester specimens were tested in a TA Instruments Model Q800 DMA using single-cantilever clamp with a span of $17.5 \mathrm{~mm}$ and pre-load stress of $3 \mathrm{MPa}$. The preload stress of $3 \mathrm{MPa}$ was chosen due to apply the linear viscoelastic theory at low stresses. Two samples were tested from each configuration.

Short term creep tests were carried out by subjecting the samples to a constant load over 30 minutes duration at isothermal temperatures in the DMA. The room temperature (RT) varied between $30^{\circ} \mathrm{C}$ and $32^{\circ} \mathrm{C}$. A temperature range of $30^{\circ} \mathrm{C}$ through $100^{\circ} \mathrm{C}$ was chosen, as this covered the glass transition temperature for all the nanocomposites considered in this research. The sample was initially equilibrated at $30^{\circ} \mathrm{C}$ for about 4 minutes to make sure that the sample temperature settles down. After equilibrium, the sample was subjected to a fixed stress of $3 \mathrm{MPa}$ for about 30 minutes. The temperature was then incremented by $4^{\circ} \mathrm{C}$ and the above procedure repeated till the final temperature of $100^{\circ} \mathrm{C}$.

In the stress relaxation mode, the sample was held at a constant strain and the stress level measured as a function 
of time over the same temperature range. The method segments executed during the relaxation test was the same as that used in creep. The sample is initially equilibrated at RT for about 4 minutes, and then displaced 0.01 strain for 30 minutes. The temperature was then incremented by $4^{\circ} \mathrm{C}$ and the process repeated until the final temperature of $100^{\circ} \mathrm{C}$.

\section{Analysis and Computation}

\subsection{Linear Viscoelastic Theory}

A viscoelastic material is characterized by possessing both viscous and elastic behavior. Elastic material is one which returns all the energy stored during loading after the load is removed [12]. As a result, the stress and strain response for elastic materials moves totally in phase. For elastic materials, Hook's law applies, where the stress is proportional to the strain, and the modulus is defined at the ratio of stress and strain. A purely viscous material returns none of the energy stored during loading. All the energy dissipated as "pure bending" once the load is removed. In this situation, the stress is proportional to the strain rate rather than strain. These materials, known as inelastic materials, have only damping, instead of stiffness. Both of these two types are ideal in existence. The real-life materials fall into neither of the above categories. These are called viscoelastic materials. Some of the energy stored in a viscoelastic system is recovered upon removal of the load, and the remainder is dissipated as heat [12]. Figure 2 [12] describes the cyclic stress at a loading frequency of $\omega$ is out-of-phase with the strain by certain angle $\phi$, where $0<\phi<\pi / 2$. The angle $\phi$ is a measure of the materials damping level; the larger angle denotes greater damping. The viscoelastic modulus is represented by a complex quantity. The real part of this complex parameter, known as storage modulus $\left(E_{1}\right)$, relates the elastic behavior of the material, and defines the

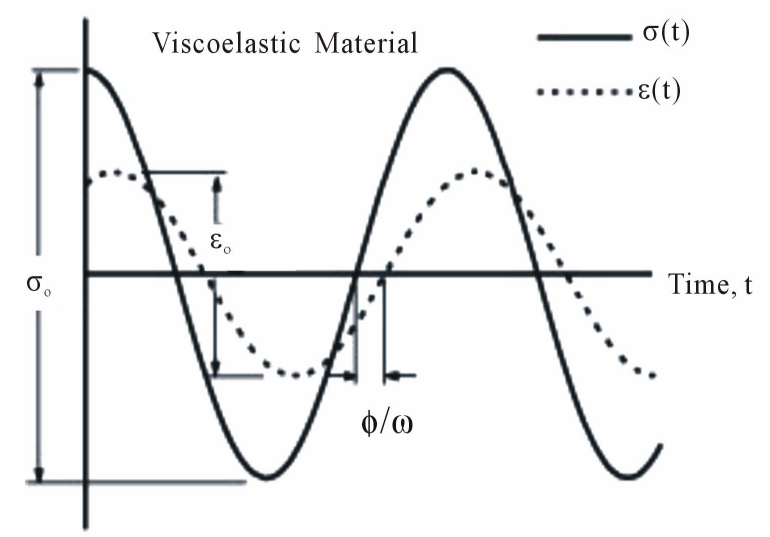

Figure 2. Cyclic stress and strain curves vs. time for a viscoelastic material [12]. stiffness. The imaginary component, known as loss modulus $\left(E_{2}\right)$, explains the material's viscous behavior, and defines the ability of energy dissipation of the material. The complex viscoelastic modulus $\left(E^{*}\right)$ is defined as:

$$
E^{*}=E_{1}+i E_{2}=\frac{\sigma_{0}}{\varepsilon_{0}} e^{i \varphi}
$$

\subsection{Time-Temperature Superposition (TTS)}

Molecular motion in materials occurs at larger rates under elevated temperatures. The time-temperature superposition principle is based on this temperature dependent response of the materials. The change in property which occurs relatively quickly at higher temperatures can be made to appear as if they occurred at longer times or lower frequencies simply by shifting the data with respect to time (1/frequency) [11]. By shifting the data with respect to frequency to a reference curve, a master curve is generated, which covers time (frequencies) outside the accessible range. The shifting mechanism used to shift a set of data upon a reference curve follows WLF [11] model. This model assumes that the fractional free volume increases linearly with respect to temperature in the transition region, and when the free volume increases, its viscosity decreases. In this model, the degree of shifting is calculated according to Equation (6):

$$
\log \left(a_{T}\right)=\frac{-C_{1}\left(T-T_{0}\right)}{C_{1}+\left(T-T_{0}\right)}
$$

\section{Results and Discussion}

\subsection{Modulus}

Figures 3 shows the storage modulus variations with temperature for brominated vinyl ester nanocomposites with the single-frequency test. Addition of CTBN to graphite reinforcement shifted the drop of storage modulus to higher temperature.

Figure 4 shows the detrimental effect of CTBN reinforcement in storage modulus with respect to $\mathrm{xGnP}$ presented at $30^{\circ} \mathrm{C}$. Figures 5 and $\mathbf{6}$ show the storage modulus variations with temperature for brominated vinyl ester nanocomposites with the multi-frequency tests. It can be observed that the modulus remains higher at higher frequency up to the glass transition temperature.

\subsection{Glass Transition}

Figures 7 shows the loss factor variation with temperature for brominated vinyl ester nanocomposites at single frequency. Figure 8 shows a marginal increase of glass transition temperature in nanocomposites with CTBN addition. 


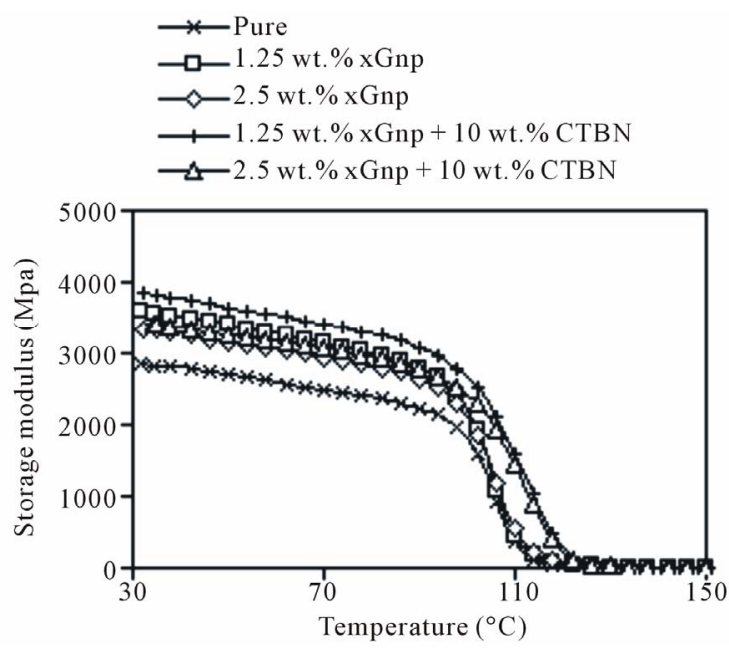

Figure 3. Storage modulus for brominated vinyl ester nanocomposites at single-frequency.

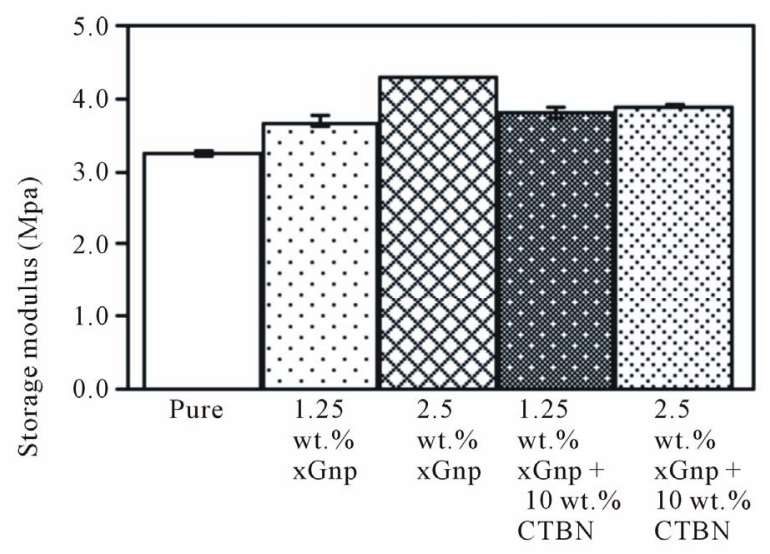

Brominated vinyl ester nanocomposites

Figure 4. Storage modulus at initial temperature for brominated vinyl ester nanocomposite.

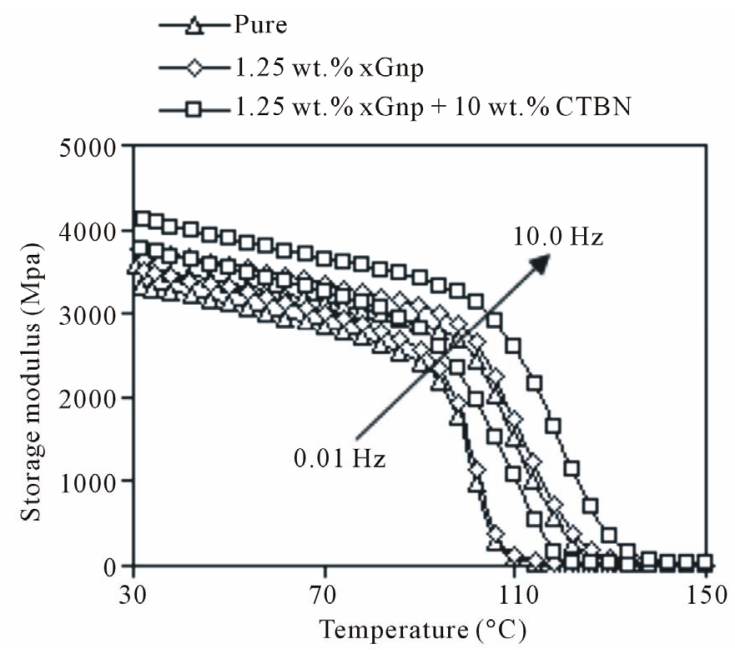

Figure 5. Storage modulus for $1.25 \mathrm{wt} \%$ reinforced brominated vinyl ester nanocomposites at multi-frequency.

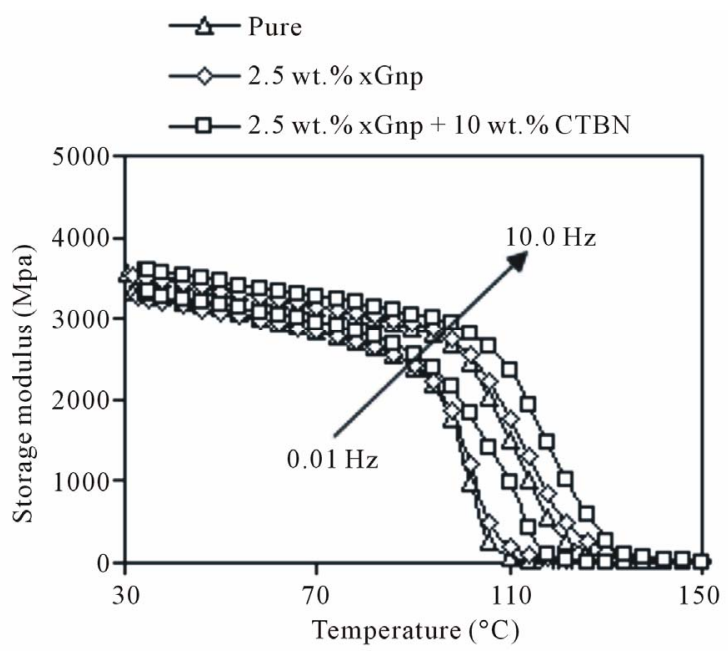

Figure 6. Storage modulus for $2.5 \mathrm{wt} \%$ reinforced brominated vinyl ester nanocomposites at multi-frequency.

$$
\begin{aligned}
& \rightarrow \text { Pure } \\
& \longrightarrow \text { - } 1.25 \text { wt. \% xGnp } \\
& \multimap-2.5 \text { wt. } \% \text { xGnp } \\
& \longrightarrow 1.25 \text { wt. } \% \text { xGnp }+10 \text { wt. } \% \text { CTBN } \\
& \neg-2.5 \mathrm{wt} . \% \times \mathrm{xnp}+10 \mathrm{wt} . \% \mathrm{CTBN}
\end{aligned}
$$

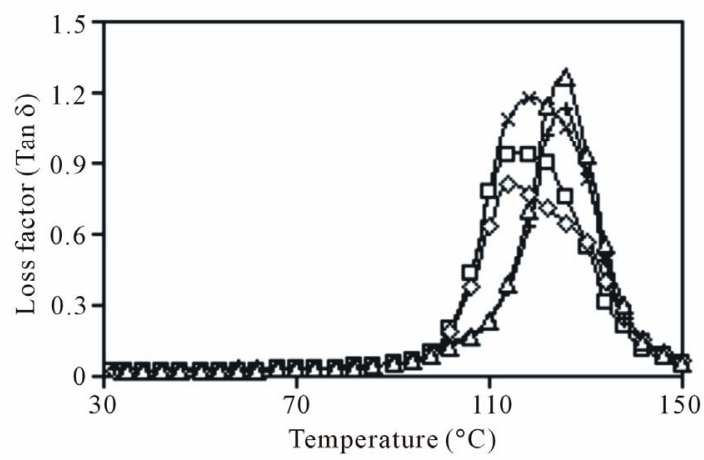

Figure 7. Loss factor for brominated vinyl ester nanocomposites at single-frequency.

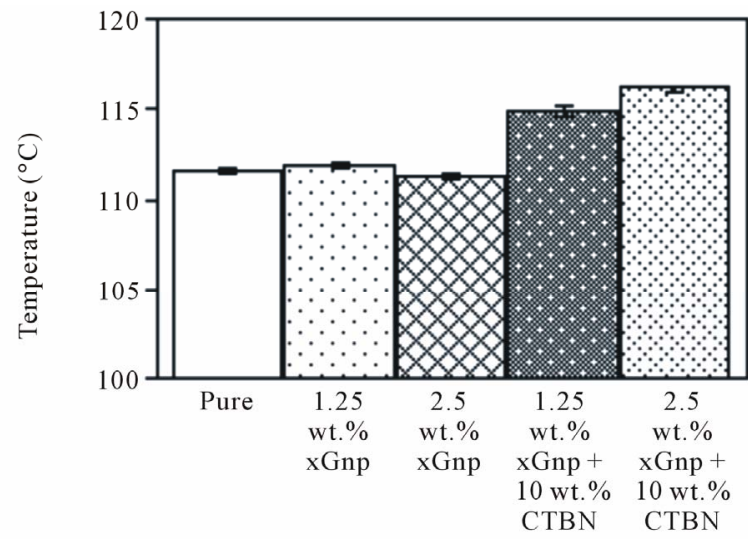

Brominated vinyl ester nanocomposites

Figure 8. Glass transition temperature for brominated vinyl ester nanocomposites. 
Figures $\mathbf{9}$ and $\mathbf{1 0}$ show the loss factor variations in multi-frequency tests. CTBN inclusion in graphite reinforcement contributed in maintaining the peak loss factor within a higher temperature range during glass transition $\left(114^{\circ} \mathrm{C}\right.$ to $\left.116^{\circ} \mathrm{C}\right)$.

\subsection{Damping}

Tan-delta, defined as the ratio of loss modulus to storage modulus, is a measure of inherent material damping. Peak of Tan-delta is the region over which material experiences a transition from glassy to a leathery behavior, associated with the onset of short range molecular segments motion, of which all are initially frozen $[12,13]$. CTBN addition resulted in greater value of Tan $\delta$ peak showing more inherent material damping as shown in Figure 11, indicating the possibility of higher energy absorption.

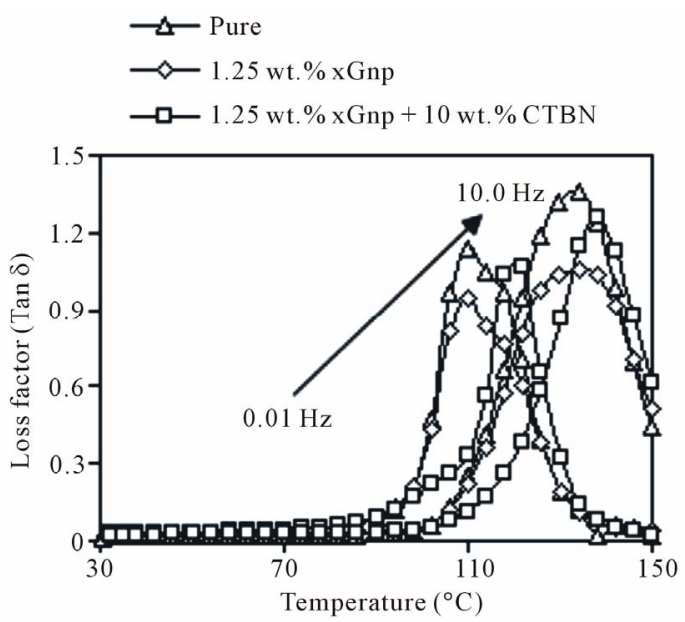

Figure 9. Loss factor for $1.25 \mathrm{wt} \%$ reinforced brominated vinyl ester nanocomposites at multi-frequency.

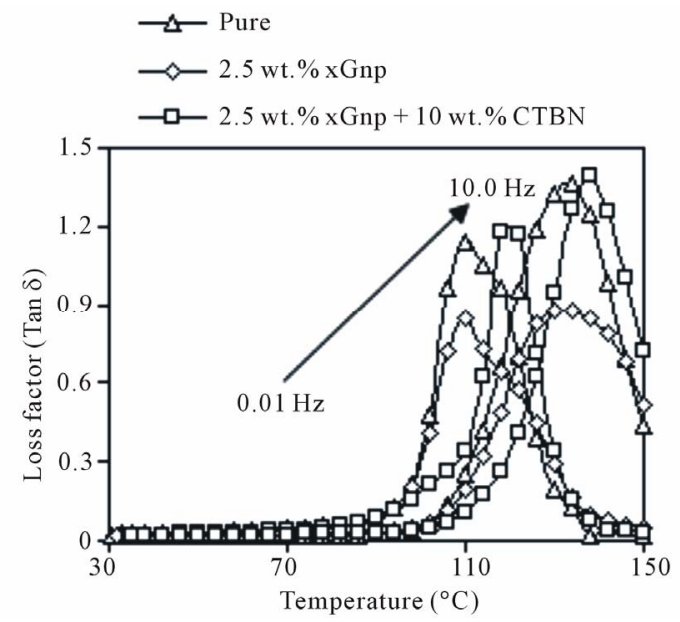

Figure 10. Loss factor for $2.5 \mathrm{wt} \%$ reinforced brominated vinyl ester nanocompposites at single-frequency.

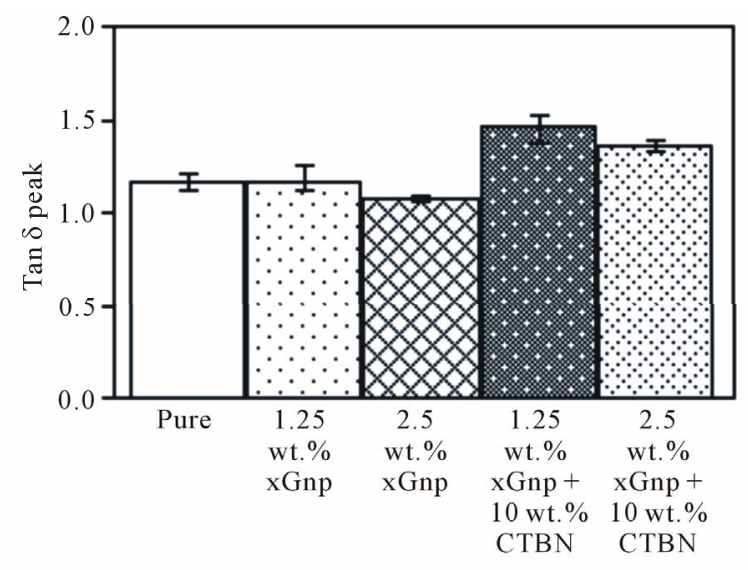

Brominated vinyl ester nanocomposites

Figure 11. Tan-delta peaks for brominated vinyl ester nanocomposites.

\subsection{Long-Term Dynamic Properties}

Since the glass transition temperature for nanocomposites is observed to be variable for different compositions, a reference temperature of $50^{\circ} \mathrm{C}$ was chosen to generate master curves for storage modulus. To perform this, data from higher temperature experiments in the lower portion of the plot are shifted to the left (lower frequencies) and curves corresponding to the temperatures lower than $50^{\circ} \mathrm{C}$ are shifted to the right [11].

Figure 12 shows the generated master curves of storage modulus over an extended period of time. From Figure 12, all vinyl ester nanocomposites were observed to maintain their rigidity (at $50^{\circ} \mathrm{C}$ ) with an average dynamic storage modulus of ( $2.5 \mathrm{GPa}$ ) over a period of $10^{10}$ sec (321.5 years), from where the vinyl ester nanocomposites impregnated with CTBN starts to show improvement. This is significant on the long term behavior of reinforced vinyl ester with CTBN.

\subsection{Creep and Stress-Relaxation}

Shape of the creep and relaxation curves for brominated vinyl ester is strongly dependent on temperature observed in this experiment (Figures 13 and 14). The effect of temperature on creep and relaxation behavior of brominated vinyl ester, $1.25 \mathrm{wt}$ percent $\times \mathrm{GnP}, 2.5 \times \mathrm{GnP}$ reinforced samples with 10 wt percent CTBN additives over 30 minutes duration were also showed similar trend. The creep deformations in the initial portion, which are pure elastic, are relatively small and associated with bending and stretching of intermolecular bonds. However, the deformation beyond the proportional limit is same as a stretching of the wrinkled molecular chains which is not recoverable instantly. Hence, the mechanical response exists in the viscoelastic linear region, where no intermolecular slippage causes permanent deformation $[12,13]$. 


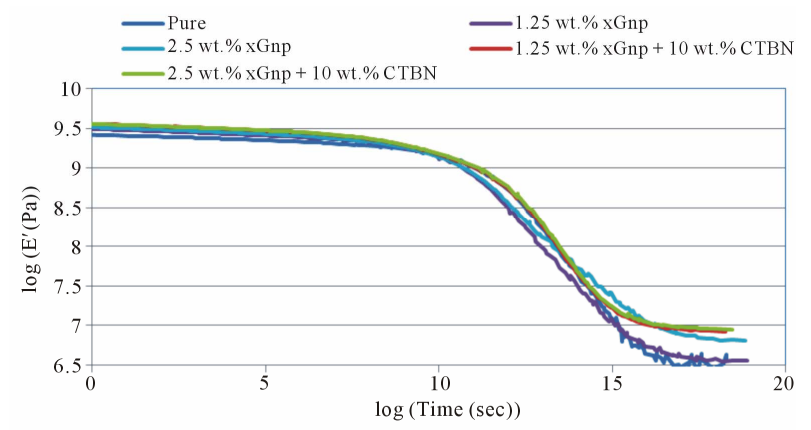

Figure 12. Master curves for brominated vinyl ester nanocompposites.

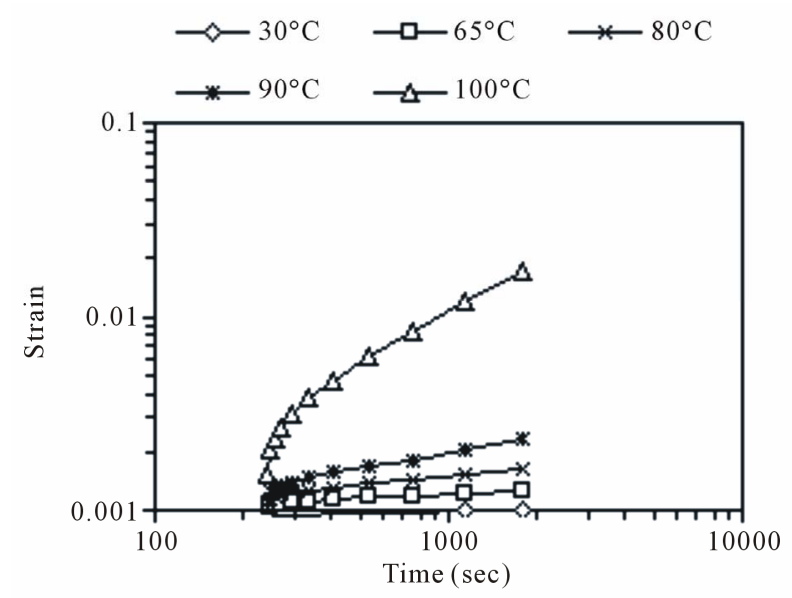

Figure 13. Creep-strain for pure brominated vinyl ester.

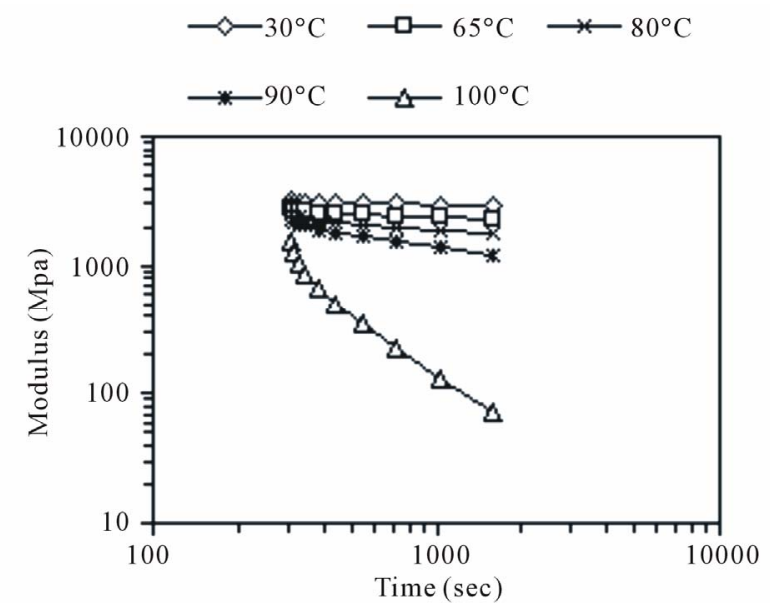

Figure 14. Relaxation modulus for pure brominated vinyl ester.

It has been observed that at $100^{\circ} \mathrm{C}$, both increment of creep-strain and decrement of modulus in stress-relaxation are less with the addition of toughening agent (Figures 15 and 16). Accordingly, addition of CTBN to $\times$ $\mathrm{GnP}$ reinforcement improves the creep resistance.

\section{Conclusions}

The effect of carboxy terminated butadiene nitrile (CTBN) on the viscoelastic behavior of Derakane 510A-40 brominated vinyl ester reinforced with 1.25 and 2.5 wt percent exfoliated graphite platelets was investigated using dynamic mechanical analyzer (DMA). Single frequency and frequency sweep across 3 decades: 0.01, 0.1, 1.0 and $10 \mathrm{~Hz}$ were applied over $30^{\circ} \mathrm{C}$ to $150^{\circ} \mathrm{C}$ temperature range at a $4^{\circ} \mathrm{C} / \mathrm{min}$ step rate. The time-temperature superposition principle was used to develop master curves of dynamic storage modulus at a reference temperature of $50^{\circ} \mathrm{C}$.

The elastic modulus was observed to decrease by a small amount with addition of CTBN to the reinforcement; along with marginal increase of the glass transition

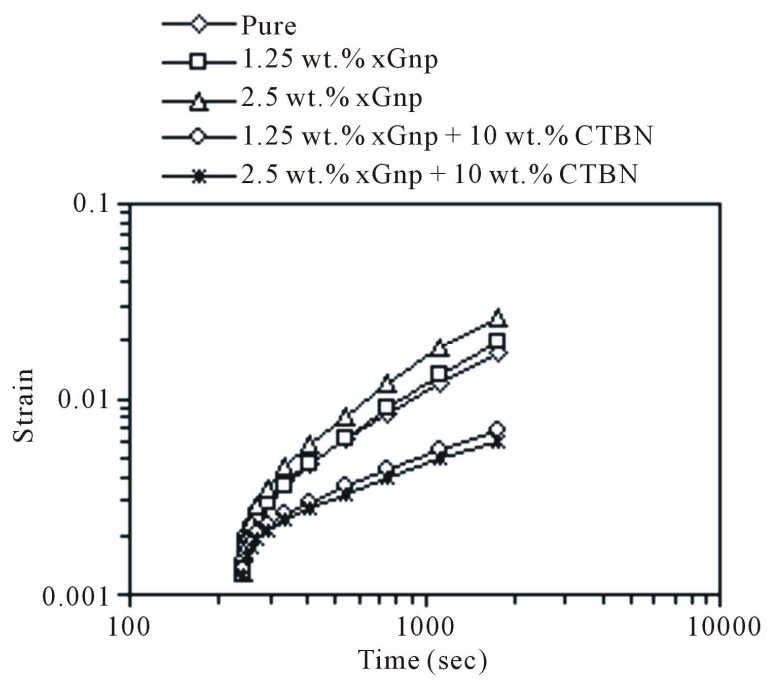

Figure 15. Creep-strain for nanocomposites at $100^{\circ} \mathrm{C}$.

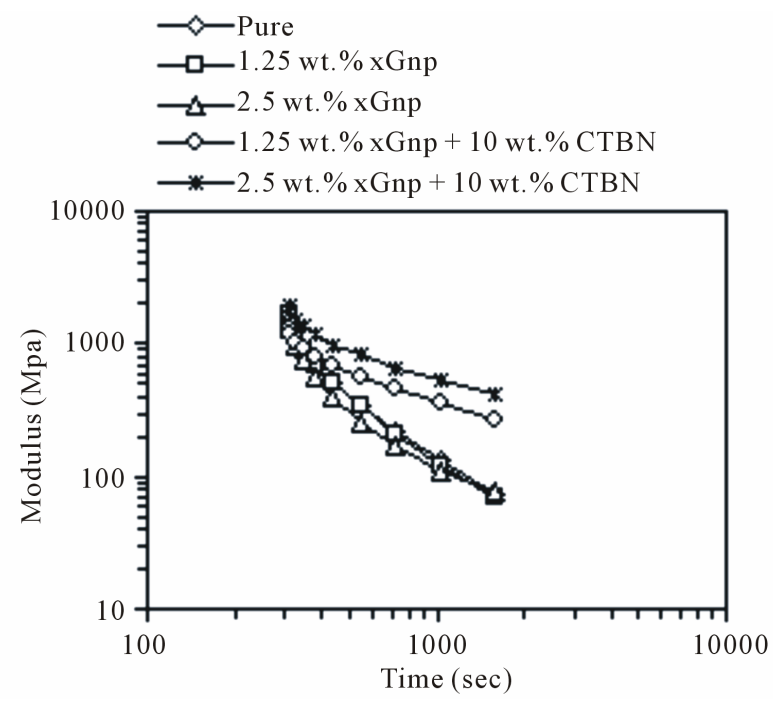

Figure 16. Relaxation modulus for nanocomposites at $100^{\circ} \mathrm{C}$. 
temperature. CTBN addition also resulted in greater value of Tan $\delta$ peak showing more inherent material damping with the possibility of higher energy absorption. Creep and relaxation curves showed the improvement of creep resistance due to the CTBN inclusion in the nano-reinforcement.

\section{Acknowledgements}

The support from ONR Grant N00014-07-1-1010, Office of Naval Research, Solid Mechanics Program (Dr. Yapa D.S. Rajapakse, Program Manager) has been acknowledged. The nanoclay and graphite platelet reinforced vinyl ester composite panels were manufactured by Dr. Larry Drzal's group at Michigan State University.

\section{REFERENCES}

[1] M. L. Auad, P. M. Frontini, J. Borrajo and M. I. Aranguren, "Liquid Rubber Modified Vinyl Ester Resins: Fracture and Mechanical Behavior," Polymer, Vol. 42, No. 8, 2001, pp. 3723-3730. doi:10.1016/S0032-3861(00)00773-4

[2] S. Balakrishnan, P. R. Start, D. Raghavan and S. D. Hudson, "The Influence of Clay and Elastomer Concentration on the Morphology and Fracture Energy of Preformed Acrylic Rubber Dispersed Clay Filled Epoxy Nanocomposites," Polymer, Vol. 46, No. 25, 2005, pp. 1125511262. doi:10.1016/j.polymer.2005.10.053

[3] J. Fröhlich, R. Thomann and R. Mülhaupt, "Toughened Epoxy Hybrid Nanocomposites Containing Both an Organophilic Layered Silicate Filler and a Compatibilized Liquid Rubber," Macromolecules, Vol. 36, No. 19, 2003, pp. 7205-7211. doi:10.1021/ma035004d

[4] J. L. Yang, Z. Zhang, A. K. Schlarb and K. Friedrich, "On the Characterization of Tensile Creep Resistance of Polyamide 66 Nanocomposites. Part II: Modeling and Prediction of Long-Term Performance," Polymer, Vol. 47, No. 19, 2006, pp. 6745-6758.

\section{doi:10.1016/j.polymer.2006.07.060}

[5] A. Pegoretti, J. Kolarik, C. Peroni and C. Migliaresi, "Recycled Polyethylene Terephthalate Layered Silicate Nanocomposites: Morphology and Tensile Mechanical Properties," Polymer, Vol. 45, No. 8, 2001, pp. 2751-2759. doi:10.1016/j.polymer.2004.02.015

[6] G. Galgali, C. Ramesh and A. Lele, "A Rheological Study on the Kinetics of Hybrid Formation in Polypropylene Nanocomposites," Macromolecules, Vol. 34, No. 4, 2001, pp. 852-858. doi: $10.1021 / \mathrm{ma} 000565 \mathrm{f}$

[7] A. Ranade, K. Nayak, D. Fairbrother and N. A. D'Souza, "Maleated and Non-Maleated Polyethylene Montmorillonite Layered Silicate Blown Films: Creep, Dispersion and Crystallinity," Polymer, Vol. 46, No. 18, 2005, pp. 7323 7333. doi:10.1016/j.polymer.2005.04.085

[8] J. Perez, V. A. Alvarez and A. Vasquez, "Creep Behavior of Layered Silicate/Starch Polycaprolacton Blends Nanocomposites," Materials Science and Engineering. A, Structural Materials: Properties, Microstructure and Processing, Vol. 480, No. 1-2, 2008, pp. 259-265.

[9] B. S. Chiou, E. Yee, G. Glenn and W. Orts, "Rheology of Starch-Clay Nanocomposites," Carbohydrate Polymers, Vol. 59, No. 4, 2005, pp. 467-475. doi:10.1016/i.carbpol.2004.11.001

[10] ASTM Standard D-4065-01, "Standard Practice for Plastics: Dynamic Mechanical Properties: Determination and Report of Procedure,” ASTM International, 2000.

[11] TA Instruments, "Dynamic Mechanical Analyzer, Q SeriesTM, Getting Started Guide," Revision F, New Castle, 2004. http://www.adhesivesmag.com

[12] J. D. Ferry, "Viscoelastic Properties of Polymers", 3rd Edition, John Wiley \& Sons Inc., New York, 1980.

[13] A. Almagableh, P. R. Mantena and A. Alostaz, "Creep and Stress Relaxation Modeling of Nanoclay and Graphite Platelet Reinforced Vinyl Ester Nanocomposites," Journal of Applied Polymer Science, Vol. 115, No. 3, 2009, pp. 1635-1642. doi:10.1002/app.31152 